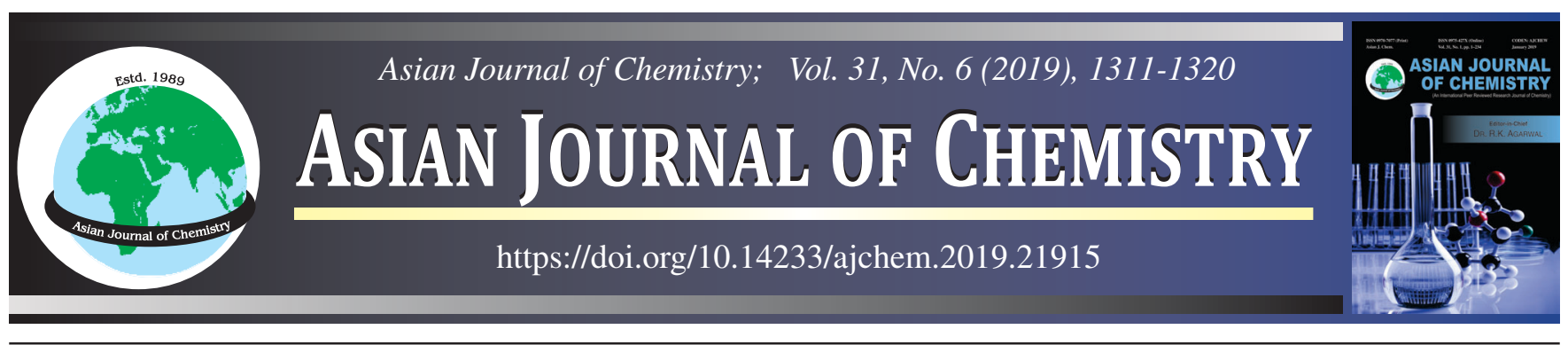

\title{
Synthesis and Characterization of 2-Phenylpyrazoline Derivatives and Evaluation of their Activities against Antimicrobial and Breast Cancer Cell Line in vitro and in silico Studies
}

\author{
Raja Chinnamanayakar and M.R. Ezhilarasi*, ${ }^{*}$
}

Department of Chemistry, Karpagam Academy of Higher Education, Coimbatore-641021, India

*Corresponding author: E-mail: mrezhilarasi@gmail.com

Received: 4 January 2019; Accepted: 18 February 2019;

Published online: 29 April 2019;

AJC-19374

The new series of 2-phenylpyrazoline derivatives (2a-j) were synthesized and evaluated for their antimicrobial, in silico and in vitro anticancer activity was performed by MTT assay using MDA-MB-231 (human breast adenocarcinoma) cell line. The 2-phenylpyrazoline derivatives (2a-j) were obtained by the cyclization of chalcones with phenylhydrazine hydrochloride. Synthesized compounds were confirmed using FT-IR, ${ }^{1} \mathrm{H}$ NMR and ${ }^{13} \mathrm{C}$ NMR spectral data. Molecular docking studies were carried out using Auto Dock Tool version 1.5.6 and Auto dock version 4.2.5.1 docking program. in silico Docking study, compound 2d showed good binding score and good binding interaction with selected bacterial proteins and breast cancer protein. Based on this result, compound 2d was performed the anticancer activity by MTT assay method. From this result, compound $\mathbf{2 d}$ shown the $\mathrm{LC}_{50}$ value is $185.30 \pm 1.469 \mu \mathrm{g} / \mathrm{mL}$. From the antibacterial activity compound $\mathbf{2 i}$ (2,3-dichloro substituted 2-pyrazoline derivative) showed a good zone of inhibition at high concentration $(100 \mathbf{m g} / \mathrm{mL})$ as compared to other derivatives (2a-j) and compound $\mathbf{2 c}$ (fluoro substituted 2-phenylpyrazoline derivative) showed a good zone of inhibition at low concentration $(25 \mathrm{mg} / \mathrm{mL})$ compared to other derivative $(\mathbf{2} \mathbf{a}-\mathbf{j})$.

Keywords: Biphenyl Chalcone, Phenylhydrazine hydrochloride, Antimicrobial activity, Anticancer activity.

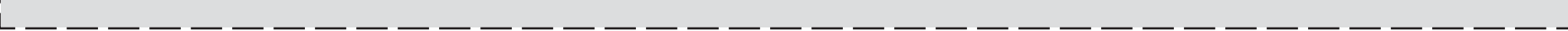

\section{INTRODUCTION}

In 20th century the most prevailing disease is cancer. The spreading of the disease is rising rapidly day by day. Surgery, radiation and chemotherapy are the most common treatment for this disease. Despite these treatments, cancer is uncontrollable and medical field needs a new approach to treat this dreadful disease. One of the most commonly used treatment methods is chemotherapy. In this method, it spreads throughout the body because the medicine and radiation used in this method travel to an entire part of the body and have some affect on the human being [1]. Therefore, we have to develop and pay more attention to update, modify and recreate the drugs and treatment methods for cancer. For medicinal chemistry and drug discovery, it is one of the urgent requirements to introduce new drugs and treatment methods for the disease [2]. The breast cancer as the second leading cause of death throughout the world is still the most frequently identified cancer in woman [3]. The literature clearly indicated that more than $90 \%$ of cancer patients die due to chronic tumor metastases. Despite the presence of a large number of anticancer drugs, no currently available agents can eradicate cancer cells without harming normal tissues. Thus, the development of newer chemotherapeutic scaffolds which with selectively act on the target without side effects has become a primary objective of medicinal chemists [4].

The chalcones are the convenient intermediate for the synthesis of pyrazoline derivatives. It has been reported various biological activities, such as muscle relaxant, tranquilizing, psychoanalytic, anticonvulsant, antidepressant and antihypertensive activities [5,6]. Pyrazolines are very useful synthone in organic synthesis. Among various pyrazoline derivatives, 2-pyrazolines derivative of compounds is mostly studied [7]. Pyrazoline compounds have adjacent two nitrogen atom occur from saturated and partially saturated pyrazoles in biologically active compounds and natural products [8]. Pharmacologically interesting heterocyclic systems like pyrazoline derivatives have been widely studied to their pharmacological activities such as antitumor, anti-inflammatory, antiparasitary, anticonvulsant, antimicrobial, antinociceptives, antimalarial,

This is an open access journal, and articles are distributed under the terms of the Creative Commons Attribution-NonCommercial-ShareAlike 4.0 (CC BY-NC-SA 4.0) International License which allows readers to freely read, download, copy, distribute, print, search, or link to the full texts of its articles and to use them for any other lawful non-commercial purpose as long as the original source is duly acknowledged. 
Alzheimer, Huntington and inflammatory arthritis, anticancer, antiviral, antioxidant, antiamoebic, antifungal, antidiabetic, cytotoxic and pesticidal properties [9]. In our previous studies, we synthesized several 1-thiocarbamoyl derivatives and tested them for antimicrobial activity and in silico activity. We reported that in vitro antimicrobial activity and in silico activity of 1-thiocarbamoyl substituted pyrazole derivatives [10].

A new series of 2-phenylpyrazoline derivatives are formed by cyclization of chalcones with phenylhydrazine hydrochloride. The chemical structures of 2-phenylpyrazoline derivatives was confirmed using FT-IR, ${ }^{1} \mathrm{H}$ NMR and ${ }^{13} \mathrm{C}$ NMR spectral data. in silico Studies were carried out for synthesized 2-phenyl pyrazoline compounds (2a-j) using bacterial proteins (1UAG, 3UDI and 2X5O) and breast cancer protein (1OQA). Based on the high binding score, the best compound was performed to in vitro anticancer activity by MTT assay. Furthermore, antimicrobial activity was carried out using different strains (Staphylococcus aureus, Klebsiella pneumonia, Escherichia coli and Candida albicans) by agar disc diffusion method.

\section{EXPERIMENTAL}

General procedure for the synthesis of $E$-3-(phenyl)1-(diphenyl-2-yl)-3-arylprop-2-en-1-one derivatives (1a-j): Various substituted aldehydes (1a-j, $0.1 \mathrm{~mol})$ and 4-acetyl biphenyl $(0.1 \mathrm{~mol})$ were taken in a $250 \mathrm{~mL}$ Erlenmeyer flask and to this approximately added nearly $30-35 \mathrm{~mL}$ of ethanol containing $20 \%$ of $\mathrm{NaOH}$ solution. This mixture was stirred well for $3 \mathrm{~h}$, then this mixture was transferred to $500 \mathrm{~mL}$ beaker containing pieces of ice cubes and kept overnight at room temperature. The solid obtained is a chalcone, which was filtered, dried and recrystallized using ethanol. Finally, the purity of the compound was checked by TLC using $\mathrm{CHCl}_{3}$ as a solvent [10].

General procedure for the synthesis of 4,5-dihydro-1phenyl-3-diphenyl-5-phenyl-1 $H$-pyrazole derivatives $(\mathbf{2 a - j})$ : Substituted chalcone (1 mol) and phenylhydrazine hydrochloride ( $1 \mathrm{~mol}$ ) was taken in a $250 \mathrm{~mL}$ round bottom flask containing $40 \mathrm{~mL}$ ethanol. After, $1 \mathrm{~mol}$ of sodium acetate was dissolved in $10 \mathrm{~mL}$ acetic acid in a $100 \mathrm{~mL}$ beaker. Then, the solution was added to the round bottom flask. After that the reaction mixtures was refluxed for 14-16 h. Completion of the reaction was monitored by TLC using $\mathrm{CHCl}_{3}$ used as a solvent. This reaction mixture was poured into crushed ice and kept in overnight at room temperature. Then these precipitate was filtered, dried and recrystallized using ethanol. The purity of the compound was checked by TLC using $\mathrm{CHCl}_{3}$ as a solvent (Scheme-I).

\section{Spectral data}

4,5-Dihydro-1-phenyl-3-diphenyl-5-phenyl-1H-pyrazole (2a): Yield 81\%; m.p: $181{ }^{\circ} \mathrm{C}$; solid yellow colour; IR ( $\mathrm{KBr}$, $\left.v_{\max }, \mathrm{cm}^{-1}\right): 1598.71(\mathrm{C}=\mathrm{N}), 1513.85(\mathrm{C}=\mathrm{C}), 1426.01(\mathrm{C}-\mathrm{N})$ 3067.13 (Ar-CH); ${ }^{1} \mathrm{H}$ NMR $\left(\mathrm{CDCl}_{3}\right) ; 400 \mathrm{MHz}, \delta, \mathrm{ppm}(J$, $\mathrm{Hz}): 3.06\left(1 \mathrm{H}, \mathrm{dd}, \mathrm{H}_{4 \mathrm{a}}, J_{4 \mathrm{a}, 4 \mathrm{~b}} 17.4 \mathrm{~Hz}, J_{4 \mathrm{a}, 5 \mathrm{a}} 6.2 \mathrm{~Hz}\right) ; 3.91(1 \mathrm{H}, \mathrm{dd}$, $\left.\mathrm{H}_{4 \mathrm{~b}}, J_{4 \mathrm{~b}, 4 \mathrm{a}} 16.4 \mathrm{~Hz}, J_{4 \mathrm{~b}, 5 \mathrm{a}} 12.8 \mathrm{~Hz}\right) ; 5.67\left(1 \mathrm{H}, \mathrm{dd}, \mathrm{H}_{5 \mathrm{a}}, J_{5 \mathrm{a}, 4 \mathrm{a}}, 12 \mathrm{~Hz}\right.$, $\left.J_{5 \mathrm{a}, 4 \mathrm{~b}} 6 \mathrm{~Hz}\right) ; 6.92-7.87(\mathrm{Ar}-\mathrm{H}) .{ }^{13} \mathrm{C}$ NMR $\delta$ : 149.72 (C3 of pyrazole ring), 43.14 (C4 of pyrazole ring), 62.51 (C5 of pyrazole ring); 145.71, 144.52, 143.87, 143.21 (IPSO carbon); 113.21, 118.78, $122.90,124.35,124.90,126.35,126.86,126.97,127.12,127.83$, 1278.49, 128.55, 129.30, 129.73, 129.91, 131.16 (Ar-C). Elemental analysis of $\mathrm{C}_{27} \mathrm{H}_{22} \mathrm{~N}_{2}$ calcd. (found) \%: C, 86.59 (86.60); H, 5.87 (5.92); N, 7.47 (7.48).

4,5-Dihydro-1-phenyl-3-diphenyl-5-(4-nitrophenyl)-1Hpyrazole (2b): Yield $84 \%$; m.p: $186^{\circ} \mathrm{C}$; solid yellow colour; IR $\left(\mathrm{KBr}, v_{\max }, \mathrm{cm}^{-1}\right): 1595.81(\mathrm{C}=\mathrm{N}), 1521(\mathrm{C}=\mathrm{C}), 1410(\mathrm{C}-\mathrm{N})$, 3053.73 (Ar-CH); ${ }^{1} \mathrm{H}$ NMR $\left(\mathrm{CDCl}_{3}\right) ; 400 \mathrm{MHz}, \delta$, ppm $(J$, $\mathrm{Hz}): 3.14\left(1 \mathrm{H}, \mathrm{dd}, \mathrm{H}_{4 \mathrm{a}}, J_{4 \mathrm{a}, 4 \mathrm{~b}} 17 \mathrm{~Hz}, J_{4 \mathrm{a}, 5 \mathrm{a}} 7 \mathrm{~Hz}\right) ; 3.93(1 \mathrm{H}, \mathrm{dd}$, $\left.\mathrm{H}_{4 \mathrm{~b}}, J_{4 \mathrm{~b}, 4 \mathrm{a}} 16.8 \mathrm{~Hz}, J_{4 \mathrm{~b}, 5 \mathrm{a}} 12.8 \mathrm{~Hz}\right) ; 5.38\left(1 \mathrm{H}, \mathrm{dd}, \mathrm{H}_{5 \mathrm{a}}, J_{5 \mathrm{a}, 4 \mathrm{a}} 12.2\right.$ $\left.\mathrm{Hz}, J_{5 \mathrm{a}, 4 \mathrm{~b}} 7 \mathrm{~Hz}\right)$; 6.81-8.21 (Ar-H). ${ }^{13} \mathrm{C}$ NMR $\delta$ : 149.81 (C3 of pyrazole ring), 43.25 (C4 of pyrazole ring), 63.81 (C5 of pyrazole ring); 147.46, 146.58, 144.35, 141.58 (IPSO carbon); 113.48, $119.85,123.88,124.25,124.61,125.50,126.35,126.66,126.97$, 127.00, 127.31, 127.49, 127.75, 129.00, 129.13, 129.24, 129.43, 131.18, 140.31 (Ar-C). Elemental analysis of $\mathrm{C}_{27} \mathrm{H}_{21} \mathrm{~N}_{3} \mathrm{O}_{2}$ calcd. (found) \%: C, 77.30 (77.31); H, $5.00(5.05)$; N, 10.01 (10.02); $\mathrm{O}, 7.62$ (7.63).

4,5-Dihydro-1-phenyl-3-diphenyl-5-(4-fluorophenyl)1H-pyrazole (2c): Yield $74 \% ;$ m.p: $169^{\circ} \mathrm{C}$; solid yellow<smiles>[X]c1ccc(C=O)cc1</smiles>

Substituted aldehyde

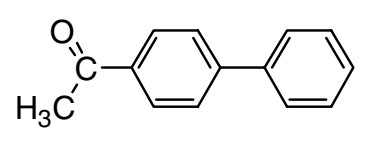

4-Acetyl biphenyl

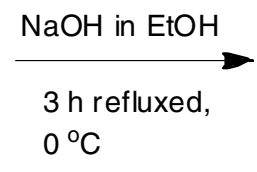

(1)

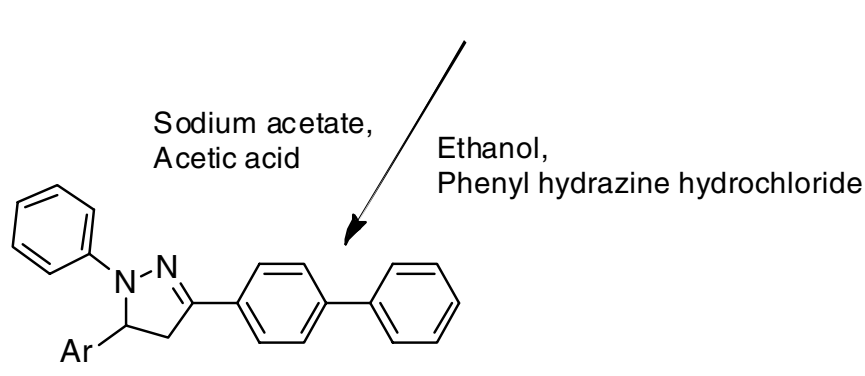

$(2 \mathrm{a}-\mathrm{j})$

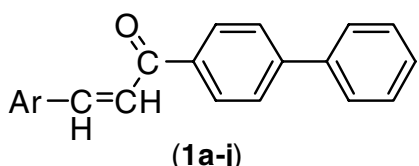

Chalcone

$$
\begin{aligned}
& \mathrm{Ar}=\mathbf{1 a}=\mathrm{C}_{6} \mathrm{H}_{5} \\
& \mathrm{Ar}=\mathbf{1} \mathbf{b}=\mathrm{C}_{6} \mathrm{H}_{4} \mathrm{NO}_{2} \\
& \mathrm{Ar}=\mathbf{1} \mathbf{c}=\mathrm{C}_{6} \mathrm{H}_{4} \mathrm{~F} \\
& \mathrm{Ar}=\mathbf{1} \mathbf{d}=\mathrm{C}_{6} \mathrm{H}_{4} \mathrm{Br} \\
& \mathrm{Ar}=\mathbf{1 e}=\mathrm{C}_{7} \mathrm{H}_{7} \\
& \mathrm{Ar}=\mathbf{1} \mathbf{f}=\mathrm{C}_{7} \mathrm{H}_{7} \mathrm{O} \\
& \mathrm{Ar}=\mathbf{1} \mathbf{g}=\mathrm{C}_{6} \mathrm{H}_{4} \mathrm{Cl} \\
& \mathrm{Ar}=\mathbf{1} \mathbf{h}=\mathrm{C}_{6} \mathrm{H}_{4} \mathrm{Cl} \\
& \mathrm{Ar}=\mathbf{1} \mathbf{i}=\mathrm{C}_{6} \mathrm{H}_{3} \mathrm{Cl} \\
& \mathrm{Ar}=\mathbf{1} \mathbf{j}=\mathrm{C}_{6} \mathrm{H}_{4} \mathrm{Br}
\end{aligned}
$$

4,5-dihydro-1-phenyl-3-diphenyl-5-substituted phenyl-1H-pyrazole 
colour; IR $\left(\mathrm{KBr}, v_{\max }, \mathrm{cm}^{-1}\right)$ : $1599.66(\mathrm{C}=\mathrm{N}), 1513.85(\mathrm{C}=\mathrm{C})$, $1401.03(\mathrm{C}-\mathrm{N}), 3034.44(\mathrm{Ar}-\mathrm{CH}) ;{ }^{1} \mathrm{H}$ NMR $\left(\mathrm{CDCl}_{3}\right) ; 400$ $\mathrm{MHz}, \delta, \operatorname{ppm}(J, \mathrm{~Hz}): 3.19\left(1 \mathrm{H}, \mathrm{dd}, \mathrm{H}_{4 \mathrm{a}}, J_{4 \mathrm{a}, 4 \mathrm{~b}} 17.3 \mathrm{~Hz}, J_{4 \mathrm{a}, 5 \mathrm{a}}\right.$ $6.9 \mathrm{~Hz}) ; 3.91\left(1 \mathrm{H}, \mathrm{dd}, \mathrm{H}_{4 \mathrm{~b}}, J_{4 \mathrm{~b}, 4 \mathrm{a}} 16.9 \mathrm{~Hz}, J_{4 \mathrm{~b}, 5 \mathrm{a}} 12.2 \mathrm{~Hz}\right) ; 5.28$ $\left(1 \mathrm{H}, \mathrm{H}_{5 \mathrm{a}}, J_{5 \mathrm{a}, 4 \mathrm{a}} 12.6 \mathrm{~Hz}, J_{5 \mathrm{a}, 4 \mathrm{~b}} 6.7 \mathrm{~Hz}\right) ; 6.79-8.18(\mathrm{Ar}-\mathrm{H}) .{ }^{13} \mathrm{C}$ NMR $\delta: 149.34$ (C3 of pyrazole ring), 45.87 (C4 of pyrazole ring), 61.53 (C5 of pyrazole ring);145.24, 145.09, 144.23, 141.58 (IPSO carbon); 115.28, 117.32, 122.88, 124.25, 124.31, $125.67,125.95,126.13,127.97,128.00,128.18,128.77,129.20$, 129.63, 129.74, 130.43, 141.18, 141.73 (Ar-C). Elemental analysis of $\mathrm{C}_{27} \mathrm{H}_{21} \mathrm{~N}_{2} \mathrm{~F}$ calcd. (found) \%: $\mathrm{C}, 82.62$ (82.63); $\mathrm{H}$, 5.35 (5.39); N, 7.13 (7.14); F, 4.83 (4.84).

4,5-Dihydro-1-phenyl-3-diphenyl-5-(4-bromophenyl)$1 \mathrm{H}$-pyrazole (2d): Yield $86 \%$; m.p.: $168^{\circ} \mathrm{C}$; solid yellow colour; IR $\left(\mathrm{KBr}, v_{\max }, \mathrm{cm}^{-1}\right): 1593(\mathrm{C}=\mathrm{N}), 1544(\mathrm{C}=\mathrm{C}), 1405(\mathrm{C}-\mathrm{N})$, $3057.58(\mathrm{Ar}-\mathrm{CH}) ;{ }^{1} \mathrm{H}$ NMR $\left(\mathrm{CDCl}_{3}\right) ; 400 \mathrm{MHz}, \delta$, ppm $(J$, $\mathrm{Hz}): 3.13\left(1 \mathrm{H}, \mathrm{dd}, \mathrm{H}_{4 \mathrm{a}}, J_{4 \mathrm{a}, 4 \mathrm{~b}} 17 \mathrm{~Hz}, J_{4 \mathrm{a}, 5 \mathrm{a}} 7 \mathrm{~Hz}\right) ; 3.87(1 \mathrm{H}, \mathrm{dd}$, $\left.\mathrm{H}_{4 \mathrm{~b}}, J_{4 \mathrm{~b}, 4 \mathrm{a}} 14.8 \mathrm{~Hz}, J_{4 \mathrm{~b}, 5 \mathrm{a}} 12.6 \mathrm{~Hz}\right) ; 5.38\left(1 \mathrm{H}, \mathrm{H}_{5 \mathrm{a}}, J_{5 \mathrm{a}, 4 \mathrm{a}} 12.4 \mathrm{~Hz}\right.$, $\left.J_{5 \mathrm{a}, 4 \mathrm{~b}} 7.2 \mathrm{~Hz}\right) ; 6.79-8.11(\mathrm{Ar}-\mathrm{H}) .{ }^{13} \mathrm{C}$ NMR $\delta: 146.39$ (C3 of pyrazole ring), 43.42 (C4 of pyrazole ring), 63.93 (C5 of pyrazole ring); $144.53,143.38,141.58,141.39$ (IPSO carbon); 113.41, 119.42, 122.75, 125.42, 126.19, 126.27, 126.98, 127.02, 127.25, 127.40, 127.57, 127.69, 127.86, 128.81, 128.87, 129.14, $129.32,130.24,131.79,140.46,140.73$ (Ar-C). Elemental analysis of $\mathrm{C}_{27} \mathrm{H}_{21} \mathrm{~N}_{2} \mathrm{Br}$ calcd. (found) \%: C, 71.52 (71.53); $\mathrm{H}, 4.63$ (4.67); N, 6.17 (6.18); Br, 17.62 (17.62).

4,5-Dihydro-1-phenyl-3-diphenyl-5-( $p$-tolyl)- $1 H$-pyrazole (2e): Yield $84 \%$; m.p. $174^{\circ} \mathrm{C}$; solid yellow colour; IR (KBr, $\left.v_{\max }, \mathrm{cm}^{-1}\right): 1589.32(\mathrm{C}=\mathrm{N}), 1523.46(\mathrm{C}=\mathrm{C}), 1414.61(\mathrm{C}-\mathrm{N})$, $3073.98(\mathrm{Ar}-\mathrm{CH}) ;{ }^{1} \mathrm{H} \mathrm{NMR}\left(\mathrm{CDCl}_{3}\right) ; 400 \mathrm{MHz}, \delta$, ppm $(J$, $\mathrm{Hz}): 3.14\left(1 \mathrm{H}, \mathrm{dd}, \mathrm{H}_{4 \mathrm{a}}, J_{4 \mathrm{a}, 4 \mathrm{~b}} 16.8 \mathrm{~Hz}, J_{4 \mathrm{a}, 5 \mathrm{a}} 7.2 \mathrm{~Hz}\right) ; 3.84(1 \mathrm{H}$, $\left.\mathrm{dd}, \mathrm{H}_{4 \mathrm{~b}}, J_{4 \mathrm{~b}, 4 \mathrm{a}} 16.8 \mathrm{~Hz}, J_{4 \mathrm{~b}, 5 \mathrm{a}} 12.4 \mathrm{~Hz}\right) ; 5.26\left(1 \mathrm{H}, \mathrm{H}_{5 \mathrm{a}}, J_{5 \mathrm{a}, 4 \mathrm{a}} 12 \mathrm{~Hz}\right.$, $\left.J_{5 \mathrm{a}, 4 \mathrm{~b}} 7.2 \mathrm{~Hz}\right) ; 2.36\left(\mathrm{~S}, 3 \mathrm{H}, \mathrm{CH}_{3}\right) ; 6.76-7.79(\mathrm{Ar}-\mathrm{H}) .{ }^{13} \mathrm{C}$ NMR $\delta: 146.41$ (C3 of pyrazole ring), 43.64 ( $\mathrm{C} 4$ of pyrazole ring), 64.34 (C5 of pyrazole ring); $21.35\left(\mathrm{~S}, 3 \mathrm{H}, \mathrm{CH}_{3}\right) ; 144.86$, 141.16, 140.56, 139.67 (IPSO carbon); 113.45, 119.12, 125.85, $126.19,127.00,127.05,127.21,127.43,127.54,128.68,128.85$, $128.89,128.95,129.93,129.86,131.84,137.28$, (Ar-C). Elemental analysis of $\mathrm{C}_{28} \mathrm{H}_{24} \mathrm{~N}_{2}$ calcd. (found) \%: $\mathrm{C}, 86.55$ (86.56); $\mathrm{H}, 6.17$ (6.18); N, 7.20 (7.21).

4,5-Dihydro-1-phenyl-3-diphenyl-5-(4-methoxyphenyl) -1H-pyrazole (2f): Yield $71 \%$; m.p.: $167{ }^{\circ} \mathrm{C}$; solid yellow colour; IR $\left(\mathrm{KBr}, v_{\max }, \mathrm{cm}^{-1}\right)$ : $1596.77(\mathrm{C}=\mathrm{N}), 1544.77(\mathrm{C}=\mathrm{C})$, 1407.78 (C-N), 3061.44 (Ar-CH); ${ }^{1} \mathrm{H}$ NMR $\left(\mathrm{CDCl}_{3}\right) ; 400 \mathrm{MHz}$, $\delta, \operatorname{ppm}(J, \mathrm{~Hz}): 3.14\left(1 \mathrm{H}, \mathrm{dd}, \mathrm{H}_{4 \mathrm{a}}, J_{4 \mathrm{a}, 4 \mathrm{~b}} 17.14 \mathrm{~Hz}, J_{4 \mathrm{a}, 5 \mathrm{a}} 7 \mathrm{~Hz}\right) ; 3.84$ $\left(1 \mathrm{H}, \mathrm{dd}, \mathrm{H}_{4 \mathrm{~b}}, J_{4 \mathrm{~b}, 4 \mathrm{a}} 13.4 \mathrm{~Hz}, J_{4 \mathrm{~b}, 5 \mathrm{a}} 9 \mathrm{~Hz}\right) ; 5.26\left(1 \mathrm{H}, \mathrm{H}_{5 \mathrm{a}}, J_{5 \mathrm{a}, 4 \mathrm{a}} 12\right.$ $\left.\mathrm{Hz}, J_{5 \mathrm{a}, 4 \mathrm{~b}} 7.2 \mathrm{~Hz}\right) ; 3.77\left(\mathrm{~s}, 3 \mathrm{H}, \mathrm{OCH}_{3}\right) ; 6.76-7.77(\mathrm{Ar}-\mathrm{H}) ;{ }^{13} \mathrm{CNMR}$ $\delta: 146.43$ (C3 of pyrazole ring), 43.63 ( $\mathrm{C} 4$ of pyrazole ring), 64.04 (C5 of pyrazole ring); 55.31 (s, $\left.3 \mathrm{H}, \mathrm{OCH}_{3}\right) ; 144.84,141.15$, 140.54, 134.67 (IPSO carbon); 113.49, 114.02, 114.54, 119.14, 125.47, 126.20, 126.35, 127.00, 127.05, 127.11, 127.22, 127.40, 127.56, 128.86, 128.97, 129.02, 130.12, 131.85, 159.02 (Ar-C). Elemental analysis of $\mathrm{C}_{28} \mathrm{H}_{24} \mathrm{~N}_{2} \mathrm{O}$ calcd. (found) \%: C, 83.13 (83.14); H, 5.93 (5.98); N, 6.92 (6.93); O, 3.95 (3.96).

4,5-Dihydro-1-phenyl-3-diphenyl-5-(2-chlorophenyl)$1 \mathrm{H}$-pyrazole (2g): Yield $77 \%$; m.p.: $177^{\circ} \mathrm{C}$; solid yellow colour; IR $\left(\mathrm{KBr}, v_{\max }, \mathrm{cm}^{-1}\right): 1596.77(\mathrm{C}=\mathrm{N}), 1521.56(\mathrm{C}=\mathrm{C}), 1447.31$ (C-N), 3055.66 (Ar-CH); ${ }^{1} \mathrm{H} \mathrm{NMR}\left(\mathrm{CDCl}_{3}\right)$ : $400 \mathrm{MHz}, \delta$, ppm
$(J, \mathrm{~Hz}): 3.15\left(1 \mathrm{H}, \mathrm{dd}, \mathrm{H}_{4 \mathrm{a}}, J_{4 \mathrm{a}, 4 \mathrm{~b}} 17.1 \mathrm{~Hz}, J_{4 \mathrm{a}, 5 \mathrm{a}} 7.2 \mathrm{~Hz}\right) ; 3.81$ $\left(1 \mathrm{H}, \mathrm{dd}, \mathrm{H}_{4 \mathrm{~b}}, J_{4 \mathrm{~b}, 4 \mathrm{a}} 16.4 \mathrm{~Hz}, J_{4 \mathrm{~b}, 5 \mathrm{a}} 12.4 \mathrm{~Hz}\right) ; 5.22\left(1 \mathrm{H}, \mathrm{H}_{5 \mathrm{a}}, J_{5 \mathrm{a}, 4 \mathrm{a}}\right.$ $\left.11.8 \mathrm{~Hz}, J_{5 \mathrm{a}, 4 \mathrm{~b}} 7.4 \mathrm{~Hz}\right) ; 6.68-7.79(\mathrm{Ar}-\mathrm{H}) .{ }^{13} \mathrm{C}$ NMR $\delta: 150.00$ (C3 of pyrazole ring), 43.65 (C4 of pyrazole ring), 64.23 (C5 of pyrazole ring); 146.44, 145.04, 141.01, 140.61 (IPSO carbon); 113.04, 113.52, 118.96, 126.18, 126.81, 127.21, 127.52, 128.91, 128.93, 130.31, 132.06 (Ar-C). Elemental analysis of $\mathrm{C}_{27} \mathrm{H}_{21} \mathrm{~N}_{2} \mathrm{Cl}$ calcd. (found) \%: C, 79.29 (79.30); H, $5.13(5.18) ; \mathrm{N}, 6.84$ (6.85); $\mathrm{Cl}, 8.66$ (8.67).

4,5-Dihydro-1-phenyl-3-diphenyl-5-(4-chlorophenyl)$1 \mathrm{H}$-pyrazole (2h): Yield $81 \%$; m.p.: $181{ }^{\circ} \mathrm{C}$; solid yellow colour; $\operatorname{IR}\left(\mathrm{KBr}, v_{\max }, \mathrm{cm}^{-1}\right): 1599.66(\mathrm{C}=\mathrm{N}), 1542.77(\mathrm{C}=\mathrm{C}), 1407.78$ (C-N), 3032.51 (Ar-CH); ${ }^{1} \mathrm{H}$ NMR $\left(\mathrm{CDCl}_{3}\right): 400 \mathrm{MHz}, \delta, \mathrm{ppm}$ $(J, \mathrm{~Hz}): 3.12\left(1 \mathrm{H}, \mathrm{dd}, \mathrm{H}_{4 \mathrm{a}}, J_{4 \mathrm{a}, 4 \mathrm{~b}} 16.8 \mathrm{~Hz}, J_{4 \mathrm{a}, 5 \mathrm{a}} 6.8 \mathrm{~Hz}\right) ; 3.86(1 \mathrm{H}$, $\left.\mathrm{dd}, \mathrm{H}_{4 \mathrm{~b}}, \mathrm{~J}_{4 \mathrm{~b}, 4 \mathrm{a}} 16.4 \mathrm{~Hz}, J_{4 \mathrm{~b}, 5 \mathrm{a}} 12.8 \mathrm{~Hz}\right) ; 5.27\left(1 \mathrm{H}, \mathrm{H}_{5 \mathrm{a}}, J_{5 \mathrm{a}, 4 \mathrm{a}} 11.8\right.$ $\left.\mathrm{Hz}, J_{5 \mathrm{a}, 4 \mathrm{~b}} 7 \mathrm{~Hz}\right) ; 3.65\left(\mathrm{~S}, 3 \mathrm{H}, \mathrm{OCH}_{3}\right) ; 6.80-8.11(\mathrm{Ar}-\mathrm{H}) .{ }^{13} \mathrm{CNMR}$ $\delta$ : 149.89 (C3 of pyrazole ring), 43.78 (C4 of pyrazole ring), 64.36 (C5 of pyrazole ring); 145.72, 144.58, 143.34, 143.27 (IPSO carbon); 113.45, 119.43, 122.40, 125.42, 126.99, 127.03, $127.25,127.34,127.37,127.42,128.32,128.86,128.91,129.04$, 129.15, 129.18, 129.39, 130.01, 131.52, 133.37, 136.47, 139.89, 140.46, 141.07 (Ar-C). Elemental analysis of $\mathrm{C}_{27} \mathrm{H}_{21} \mathrm{~N}_{2} \mathrm{Cl}$ calcd. (found) \%: C, 79.29 (79.30); H, 5.13 (5.18); N, 6.86 (6.85); $\mathrm{Cl}, 8.66$ (8.67).

4,5-Dihydro-1-phenyl-3-diphenyl-5-(2,3-dichlorophenyl)-1H-pyrazole (2i): Yield $61 \%$; m.p; $183{ }^{\circ} \mathrm{C}$; solid yellow colour; IR $\left(\mathrm{KBr}, v_{\max }, \mathrm{cm}^{-1}\right)$ : $1597.74(\mathrm{C}=\mathrm{N}), 1515.67$ $(\mathrm{C}=\mathrm{C}), 1427.04(\mathrm{C}-\mathrm{N}), 3031.86(\mathrm{Ar}-\mathrm{CH}) ;{ }^{1} \mathrm{H} \mathrm{NMR}\left(\mathrm{CDCl}_{3}\right)$ : $400 \mathrm{MHz}, \delta$, ppm $(J, \mathrm{~Hz}): 3.19\left(1 \mathrm{H}, \mathrm{dd}, \mathrm{H}_{4 \mathrm{a}}, J_{4 \mathrm{a}, 4 \mathrm{~b}} 16.6 \mathrm{~Hz}\right.$, $\left.J_{4 a, 5 a} 6.4 \mathrm{~Hz}\right) ; 3.81\left(1 \mathrm{H}, \mathrm{dd}, \mathrm{H}_{4 \mathrm{~b}}, J_{4 \mathrm{~b}, 4 \mathrm{a}} 16.9 \mathrm{~Hz}, J_{4 \mathrm{~b}, 5 \mathrm{a}} 13.4 \mathrm{~Hz}\right)$; $5.38\left(1 \mathrm{H}, \mathrm{H}_{5 \mathrm{a}}, J_{5 \mathrm{a}, 4 \mathrm{a}} 13.8 \mathrm{~Hz}, J_{5 \mathrm{a}, 4 \mathrm{~b}} 6.8 \mathrm{~Hz}\right) ; 6.73-8.21(\mathrm{Ar}-\mathrm{H})$. ${ }^{13} \mathrm{C}$ NMR $\delta: 146.63$ (C3 of pyrazole ring), 43.47 (C4 of pyrazole ring), 63.88 ( $\mathrm{C} 5$ of pyrazole ring); 56.17 (s, 3H, $\left.\mathrm{OCH}_{3}\right) ; 145.23$, 144.61, 143.14, 143.27 (IPSO carbon); 113.75, 115.43, 119.40, $125.42,126.00,127.61,127.85,128.01,128.86,128.97,129.00$, $129.34,129.77,129.89,130.01,131.32,132.37,133.51,134.89$, 138.46, 139.31,139.79, 140.56, 141.07, 159.03 (Ar-C). Elemental analysis of $\mathrm{C}_{27} \mathrm{H}_{20} \mathrm{~N}_{2} \mathrm{Cl}_{2}$ calcd. (found) \%: $\mathrm{C}, 73.13$ (73.14); $\mathrm{H}$, 4.51 (4.55); N, 6.32 (6.31); Cl, 15.99 (15.99).

4,5-Dihydro-1-phenyl-3-diphenyl-5-(3-bromophenyl)$1 \mathrm{H}$-pyrazole (2j): Yield $86 \%$; m.p.: $172{ }^{\circ} \mathrm{C}$; solid yellow colour; IR $\left(\mathrm{KBr}, \nu_{\max }, \mathrm{cm}^{-1}\right) ;{ }^{1} \mathrm{H} \mathrm{NMR}\left(\mathrm{CDCl}_{3}\right) ; 400 \mathrm{MHz}, \delta, \operatorname{ppm}(J$, $\mathrm{Hz}): 3.12\left(1 \mathrm{H}, \mathrm{dd}, \mathrm{H}_{4 a}, J_{4 a, 4 b} 16.8 \mathrm{~Hz}, J_{4 a, 5 a} 6.8 \mathrm{~Hz}\right) ; 3.83(1 \mathrm{H}, \mathrm{dd}$, $\left.\mathrm{H}_{4 \mathrm{~b}}, J_{4 \mathrm{~b}, 4 \mathrm{a}} 14.4 \mathrm{~Hz}, J_{4 \mathrm{~b}, 5 \mathrm{a}} 12.8 \mathrm{~Hz}\right) ; 5.34\left(1 \mathrm{H}, \mathrm{H}_{5 \mathrm{a}}, J_{5 \mathrm{a}, 4 \mathrm{a}} 12.8 \mathrm{~Hz}\right.$, $\left.J_{5 \mathrm{a}, 4 \mathrm{~b}} 7.2 \mathrm{~Hz}\right) ; 6.78-8.14(\mathrm{Ar}-\mathrm{H}) .{ }^{13} \mathrm{CNMR} \delta: 146.47$ (C3 of pyrazole ring), 43.76 ( $\mathrm{C} 4$ of pyrazole ring), 63.45 (C5 of pyrazole ring); 143.17, 143.38, 142.78, 141.03 (IPSO carbon); 113.17, 119.65, $122.14,123.19,124.39,125.37,126.98,127.00,127.25,127.47$, $127.98,128.00,128.66,128.81,128.87,129.13,129.54,130.01$, $131.43,138.81,139.67$ (Ar-C). Elemental analysis of $\mathrm{C}_{27} \mathrm{H}_{21} \mathrm{~N}_{2} \mathrm{Br}$ calcd. (found) \%: C, 71.52 (71.53); H, 4.63 (4.67); N, 6.17 (6.18); $\mathrm{Br}, 17.62$ (17.62).

in silico Studies: in silico Study has been carried out for synthesized new 2-phenylpyrazoline derivatives (2a-j) using bacterial proteins (1UAG, 3UDI, and 2X5O) and breast cancer protein (1OQA). Different software is used in molecular docking studies, they are Chem draw, Pyrx, Chimera and Discovery studies. 
Molecular docking studies: Molecular docking studies have been carried out using ADT (Auto Dock Tool) version 1.5.6. and Auto Dock version 4.2.5.1 docking program.

Preparation of protein: The bacterial proteins and breast cancer protein were downloaded from Protein Data Bank (PDB id: 1UAG, 3UDI, 2X50 and 10QA).

Ligand preparation: 2D structure of 2-phenylpyrazoline derivatives (2a-j) is drawn using ChemDraw Ultra 8.0 (Chemoffice 2002). After that Chem 3D Ultra 8.0 was used to convert the $2 \mathrm{D}$ structure into the $3 \mathrm{D}$ structure and the energy is minimized using semi-empirical AM1 method. All the structures are saved as PDB file format for input to ADT. Finally, all the ligand structures are saved as PDB file format to carry out molecular docking in Auto dock Vina.

Grid formation: A grid box with a dimension of $40 \times 40$ $\times 40 \AA^{3}$ in $0.375 \AA$ spacing and centered on $30.473,47.997$, 9.563 has created around the binding site of protein using ADT. The center of the box was set at ligand center and grid energy calculations have been carried out.

Docking protocol: The auto dock calculation is such as default parameters have been used and 10 docked confirmations are generated for each compound. The energy calculation is done using genetic algorithms. The outputs are exported to Chimera 1.10 and discovery studio 4.5 for visual inspection of the binding modes and interaction of the compounds with amino acid residues in the active site [11].

\section{Anticancer activity}

MTT assay: MDA-MB-231 (human breast adenocarcinoma) cell was initially procured from National Centre for Cell Sciences (NCCS), Pune, India and maintained Dulbecco's modified Eagles medium, DMEM (Sigma Aldrich, USA).

The cell line was cultured in a $25 \mathrm{~cm}^{2}$ tissue culture flask with DMEM supplemented with $10 \%$ FBS, L-glutamine, sodium bicarbonate (Merck, Germany) and the antibiotic solution containing penicillin $(100 \mathrm{U} / \mathrm{mL})$, streptomycin $(100 \mu \mathrm{g} / \mathrm{mL})$, and amphotericin B $(2.5 \mu \mathrm{g} / \mathrm{mL})$. Cultured cell lines were kept at $37{ }^{\circ} \mathrm{C}$ in a humidified $5 \% \mathrm{CO}_{2}$ incubator (NBS Eppendorf, Germany). The viability of cells was evaluated by direct observation of cells by inverted phase contrast microscope and followed by MTT assay method.

Cells seeding in 96 well plate: A two-day old confluent monolayer of cells trypsinized and the cells were suspended in $10 \%$ growth medium, $100 \mu \mathrm{L}$ cell suspension $\left(5 \times 10^{4}\right.$ cells/ well) was seeded in 96 well tissue culture plate and incubated at $37^{\circ} \mathrm{C}$ in a humidified $5 \% \mathrm{CO}_{2}$ incubator.

Preparation of compound stock: $1 \mathrm{mg}$ of sample was weighed and dissolved in $1 \mathrm{~mL}$ of DMEM using a cyclomixer. The sample solution was filtered through $0.22 \mu \mathrm{m}$ Millipore syringe filter to ensure the sterility.

Anticancer evaluation: After $24 \mathrm{~h}$ the growth medium was removed, freshly prepared each compounds in $5 \%$ DMEM was five times serially diluted by two-fold dilution $(100,50$, $25,12.5$ and $6.25 \mu \mathrm{g}$ ) in $500 \mu \mathrm{L}$ of $5 \%$ DMEM and each concentration of $100 \mu \mathrm{L}$ were added in triplicates to the respective wells and incubated at $37^{\circ} \mathrm{C}$ in a humidified $5 \% \mathrm{CO}_{2}$ incubator. Non-treated control cells were also maintained.

Anticancer assay by MTT method: $15 \mathrm{mg}$ of MTT (Sigma, M-5655) was reconstituted in $3 \mathrm{~mL}$ PBS until completely disso- lved and sterilized by filter sterilization. After $24 \mathrm{~h}$ of incubation period, the sample content in wells was removed and $30 \mu \mathrm{L}$ of reconstituted MTT solution was added to all test and cell control wells, the plate was gently shaken well and incubated at $37{ }^{\circ} \mathrm{C}$ in a humidified $5 \% \mathrm{CO}_{2}$ incubator for $4 \mathrm{~h}$. After the incubation period, the supernatant was removed and $100 \mu \mathrm{L}$ of MTT solubilization solution (DMSO, Sigma Aldrich, USA) was added and the wells were mixed gently by pipetting up and down in order to solubilize the formazan crystals. The absorbance values were measured by using microplate reader at a wavelength of 540 $\mathrm{nm}$ [12]. The percentage of growth inhibition was calculated using the following formula:

$$
\text { Viability }(\%)=\frac{\text { Mean OD samples }}{\text { Mean OD of control group }} \times 100
$$

Antimicrobial activity: The synthesis of 2-phenylpyrazoline derivatives was subjected to antimicrobial activity by agar disk diffusion method. In these studies, four different strains were used are Staphylococcus aureus, Streptococcus, Escherichia coli and Klebsiella.

Antifungal activity: The synthesized new 2-phenylpyrazoline derivatives were screened for antifungal activity using Candida albicans by agar disc diffusion method.

\section{RESULTS AND DISCUSSION}

In this work, 2-phenylpyrazoline derivatives (2a-j) were prepared by the cyclization of phenylhydrazine hydrochloride with chalcones (1a-j) in turn generated as intermediates by Aldol condensation reaction between the corresponding 4-acetyl biphenyl and substituted aldehydes in ethanolic $\mathrm{NaOH}$ solution.

Molecular docking studies for 4,5-dihydro-1-phenyl3-diphenyl-5-substituted phenyl- $1 \mathrm{H}$-pyrazole derivatives (2a-j): In the present study, in silico studies were carried out by Auto Dock Tool version 1.5.6 and Auto dock version 4.2.5.1 docking program using bacterial proteins (1UAG, 3UDI and $2 \mathrm{X50}$ ) and breast cancer protein (1OQA) (Figs. 1 and 2). The bacterial proteins (1UAG, 3UDI and 2X5O) which is involved in cell wall synthesis mechanism.

The docking studies which are reported in terms of binding affinity value, which mean the lower, the score, the better and the interactions. In ligand 2-phenylpyrazoline derivatives (2a-j) were individually docked with the bacterial proteins and breast cancer protein. The molecular docking results are shown in Table-1, which showed that 2-phenylpyrazoline derivatives (2a-j) exhibited good binding affinity score as compared to the standard drug. Based on binding affinity score, hydrophobic and hydrophilic interactions and 2-phenylpyrazoline derivatives showed better binding affinity as compared to standard drug.

The molecular docking studies show that these 2-phenylpyrazoline derivatives bind well in the active site pocket of bacterial proteins and interact with the active site of amino acid residues. The best compound of these derivatives (2a-j) have been explained as follows:

Binding affinity score: The synthesized 2-phenylpyrazoline derivatives (2a-j) were docked with bacterial protein 1UAG, 2X5O and 3UDI. From this result, 2-phenylpyrazoline derivative 

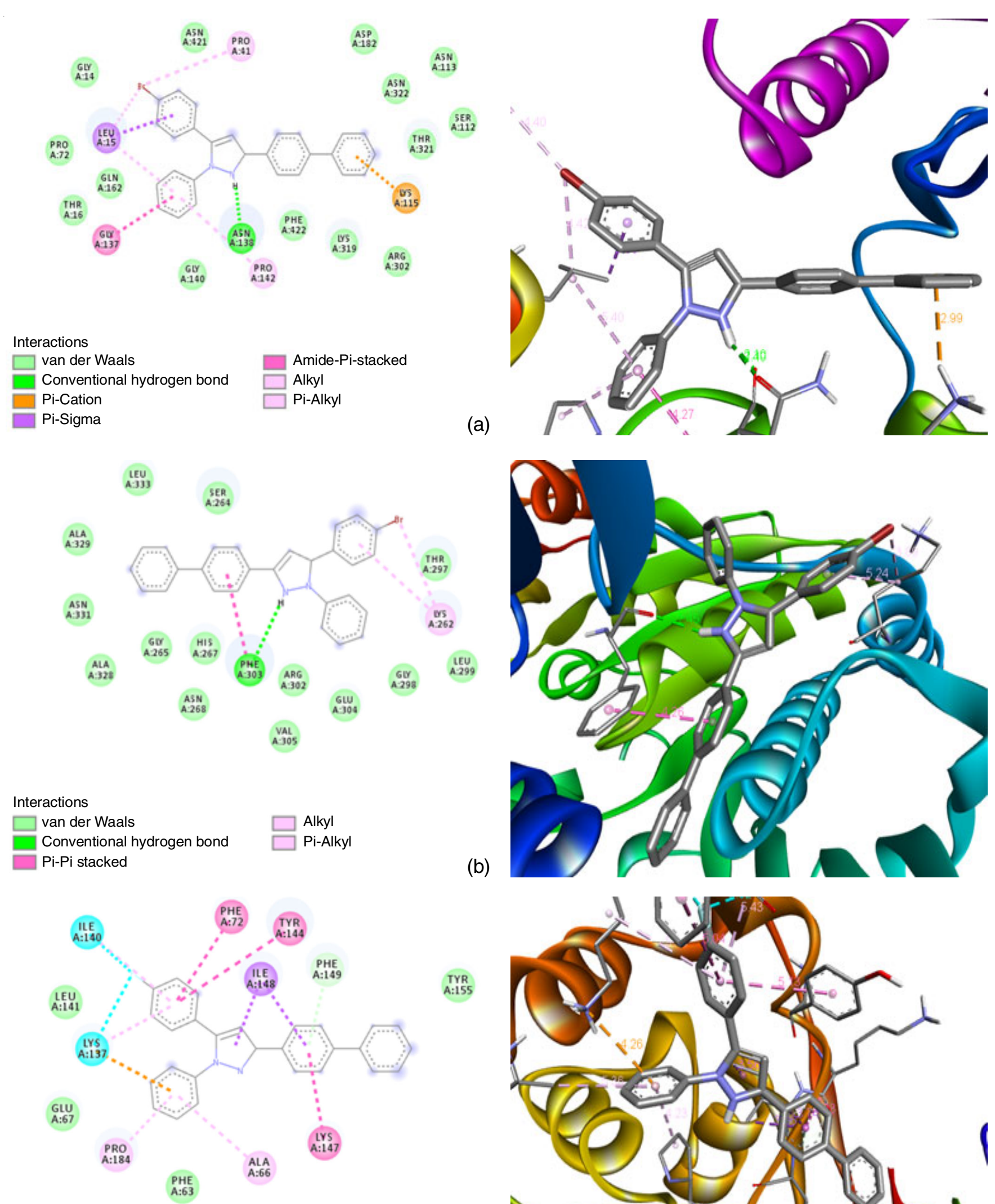

(a)
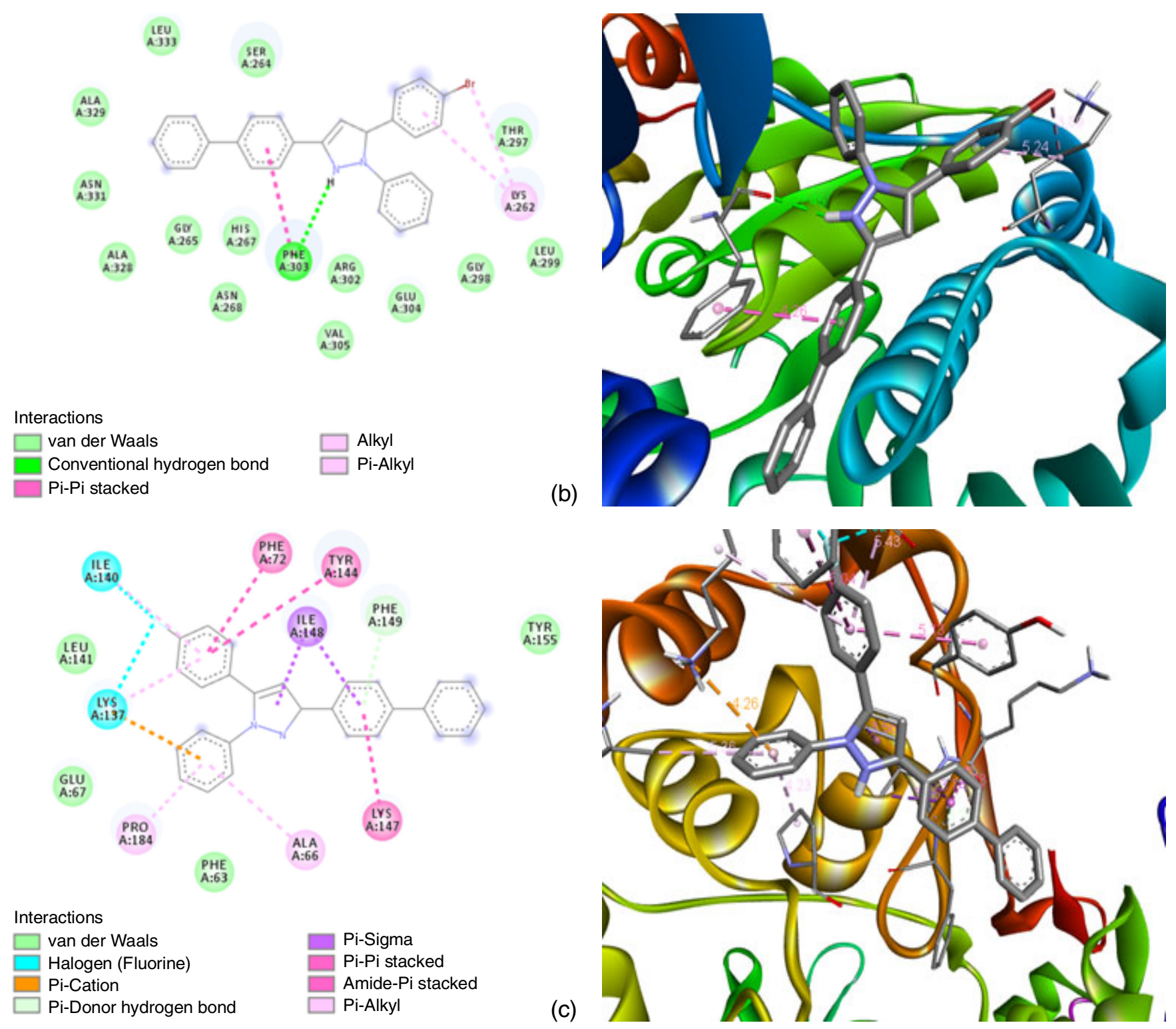

Fig. 1. (a) 2D and 3D image of compound $2 \mathbf{d}$ docked with $1 \mathrm{UAG}$ protein; (b) 2D and 3D image of compound $\mathbf{2 d}$ docked with $2 \mathrm{X} 5 \mathrm{O}$ protein, (c) compound $\mathbf{2 d}$ and 3D image of compound $\mathbf{2 d}$ docked with 3UDI protein 


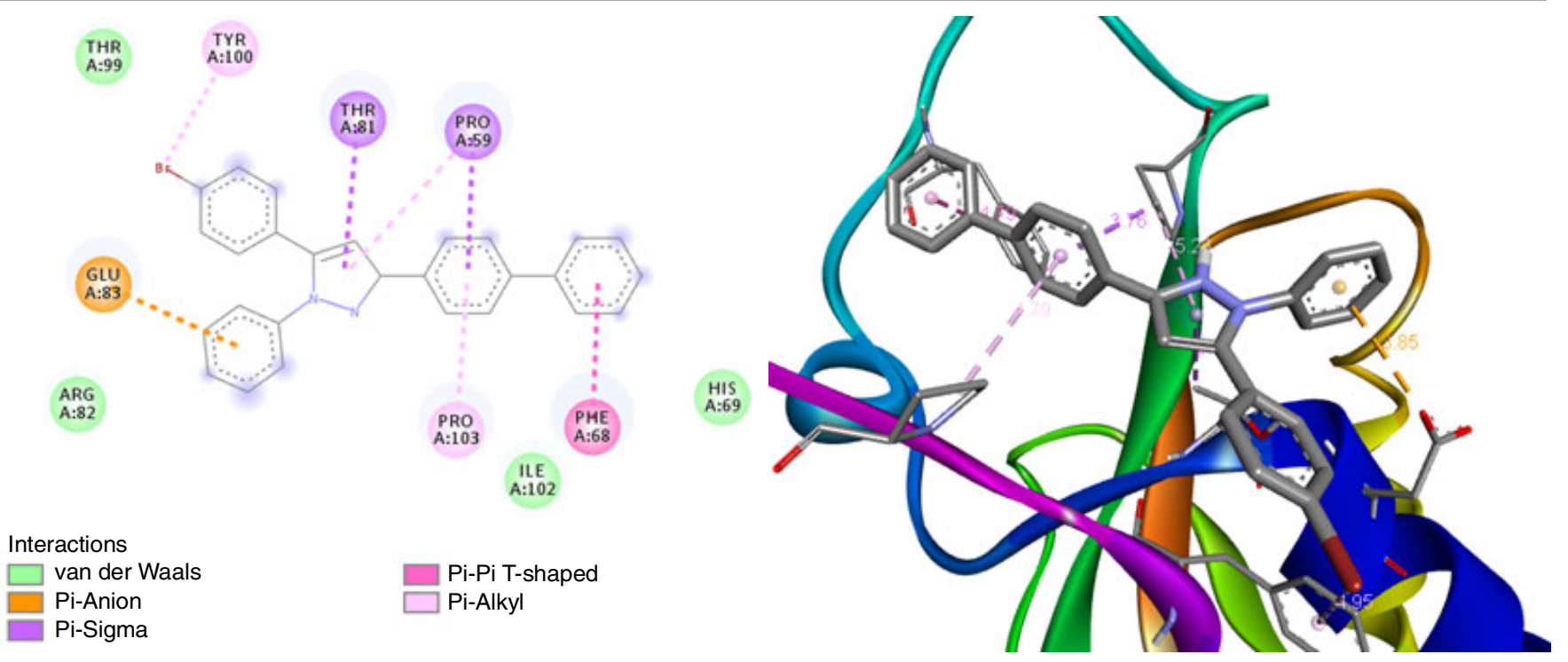

Fig. 2. 2D and 3D image of compound 4,5-dihydro-1-phenyl-3-diphenyl-5-(4-bromophenyl)-1H-pyrazole (2d) docked with breast cancer protein (1OQA)

TABLE-1

MOLECULAR DOCKING RESULTS FOR 2- PHENYL PYRAZOLINE DERIVATIVES (2a-j) DOCKED WITH DIFFERENT BACTERIAL PROTEINS

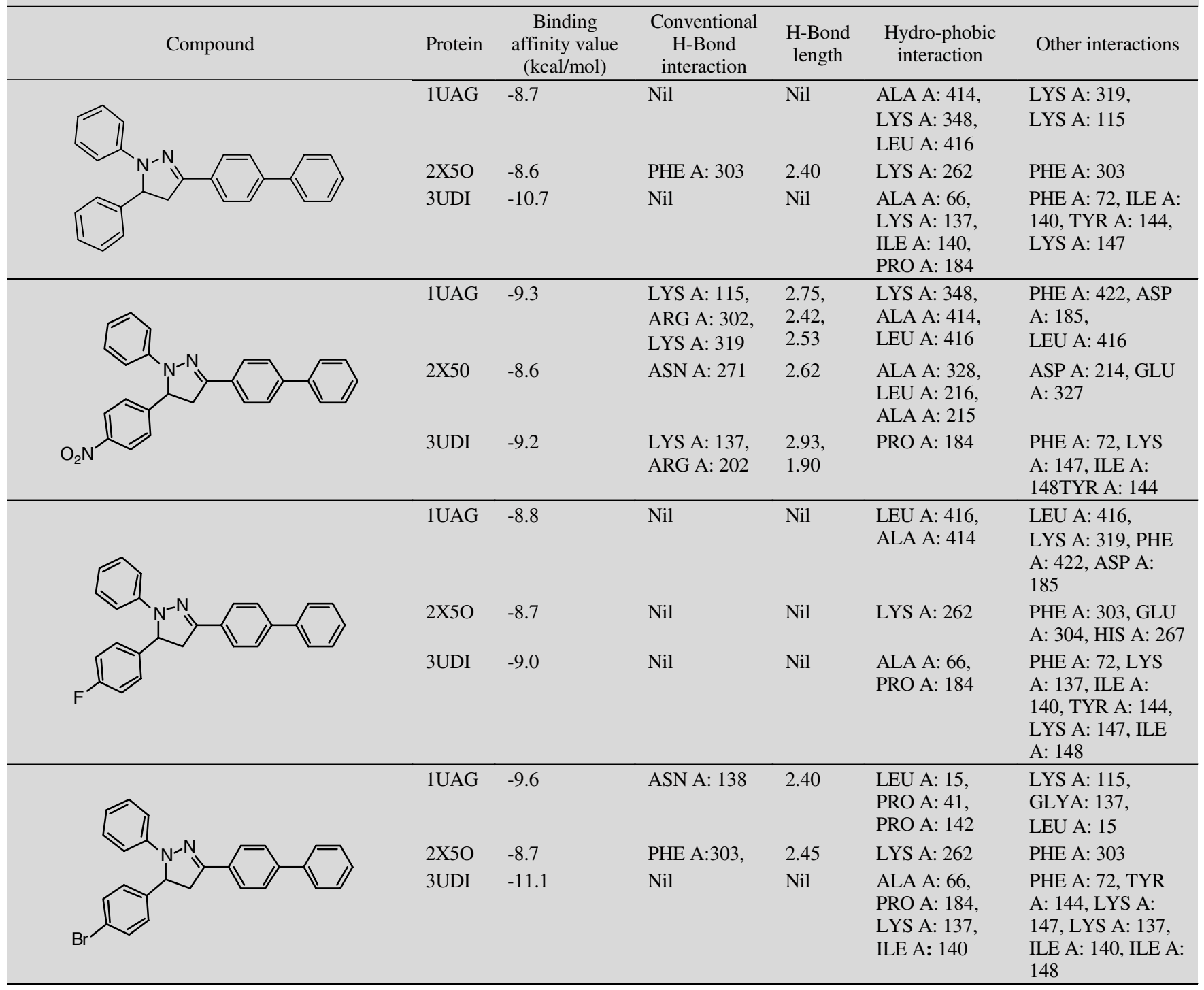




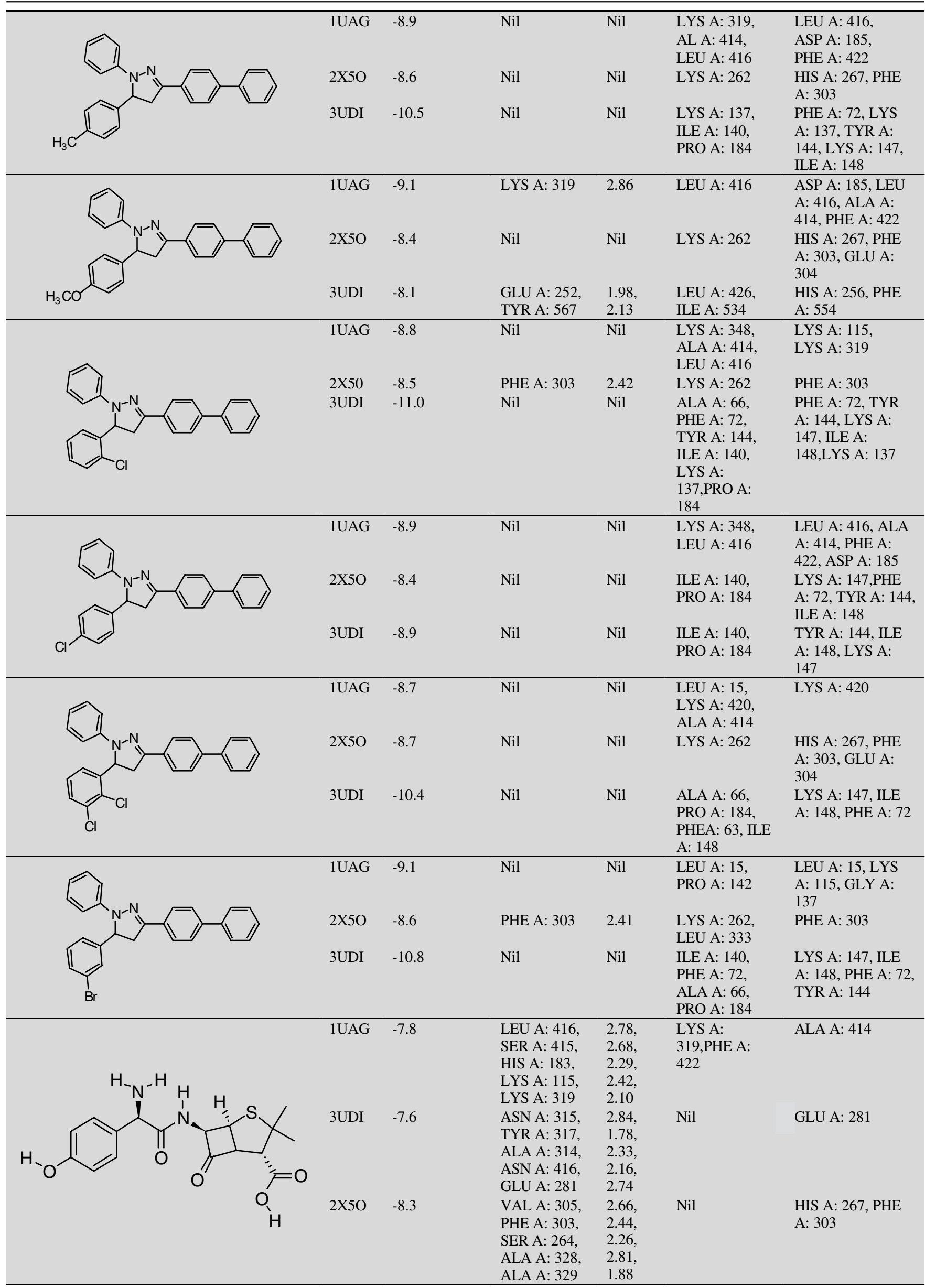


compound (2d) showed good binding affinity score (-9.6 kcal/ $\mathrm{mol},-8.7 \mathrm{kcal} / \mathrm{mol}$ and $-11.1 \mathrm{kcal} / \mathrm{mol}$ ) compared to other synthesized 2-phenylpyrazoline derivatives (2a-j except 2d) and a standard drug (amoxicillin). Other derivatives binding affinity scores are given in Table-1.

Conventional hydrogen bond interaction: Based on high binding affinity score, compound $\mathbf{2 d}$ has one conventional hydrogen bond interaction (ASNA: 138) formed with the pyrazole moiety (1UAG). The hydrogen bond distance is $2.40 \AA$. Compound 2d has one hydrogen bond interaction (PHE A: 303) with the pyrazole moiety (2X5O). The hydrogen bond distance is 2.45 $\AA$. Compound $\mathbf{2 d}$ has no hydrogen bond interaction with the 3UDI protein.
Hydrophobic interaction: Based on high binding affinity score, compound $\mathbf{2 d}$ have three hydrophobic interaction (LEU A: 15, PRO A: 41, PRO A: 142) formed with the benzene ring and bromo moiety (1UAG). Compound $\mathbf{2 d}$ have one hydrophobic interaction (LYS A: 262) formed with the benzene ring and bromo moiety. Compound $\mathbf{2 d}$ have four hydrophobic interaction (ALA A: 66, LYS A: 137, ILE A: 140, PRO A: 184) formed with 2-phenylpyrazoline benzene ring and substituted bromobenzene ring.

Molecular docking study with breast cancer protein (10QA): The synthesized new 2-phenylpyrazoline derivatives (2a-j) was docked with breast cancer protein (1OQA). The results are shown in Table-2. Thus, compound $\mathbf{2 d}$ have high binding

TABLE -2

MOLECULAR DATA FOR 2- PHENYL PYRAZOLINE DERIVATIVES (2a-j) DOCKED WITH BREAST CANCER PROTEIN

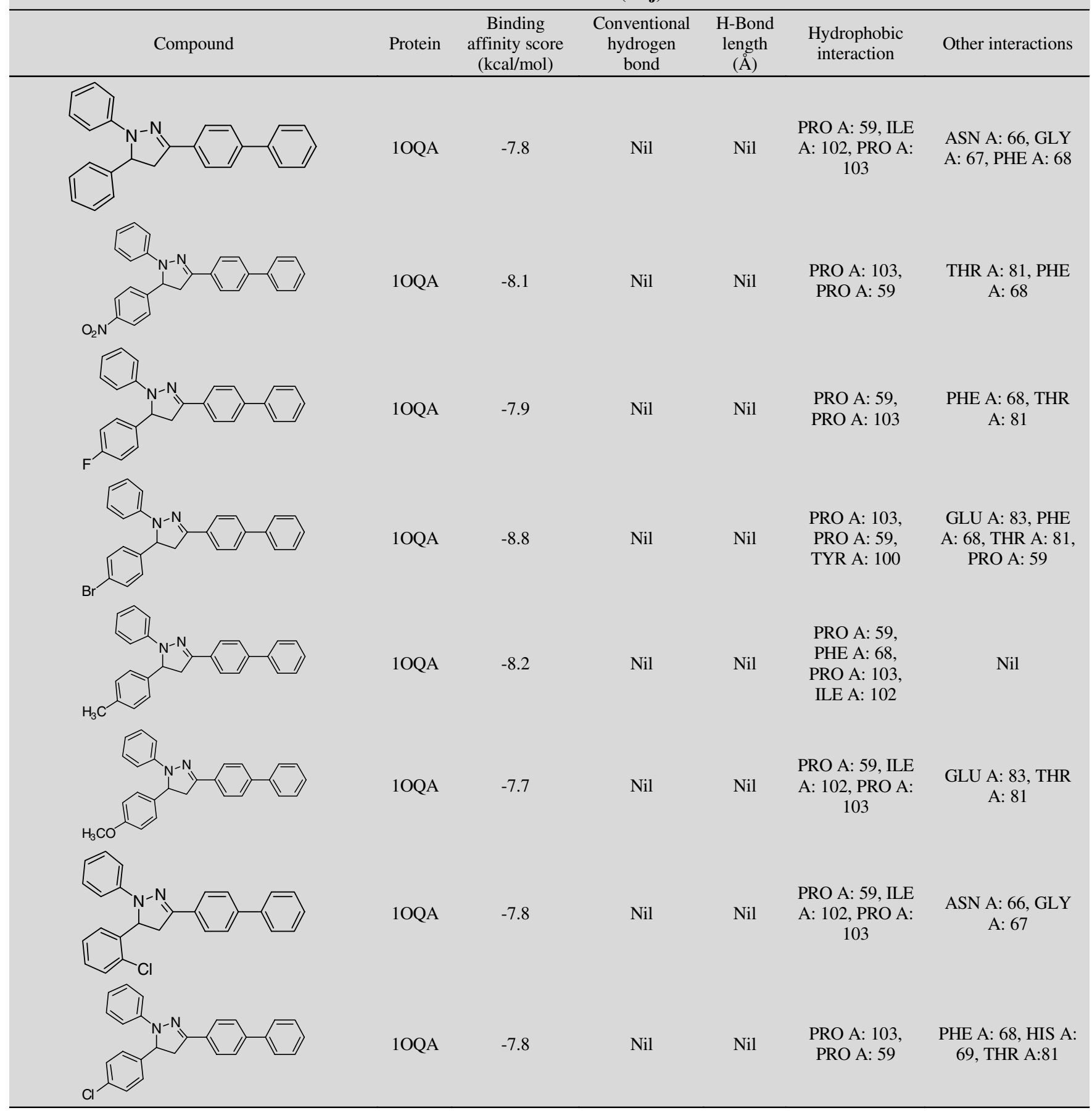




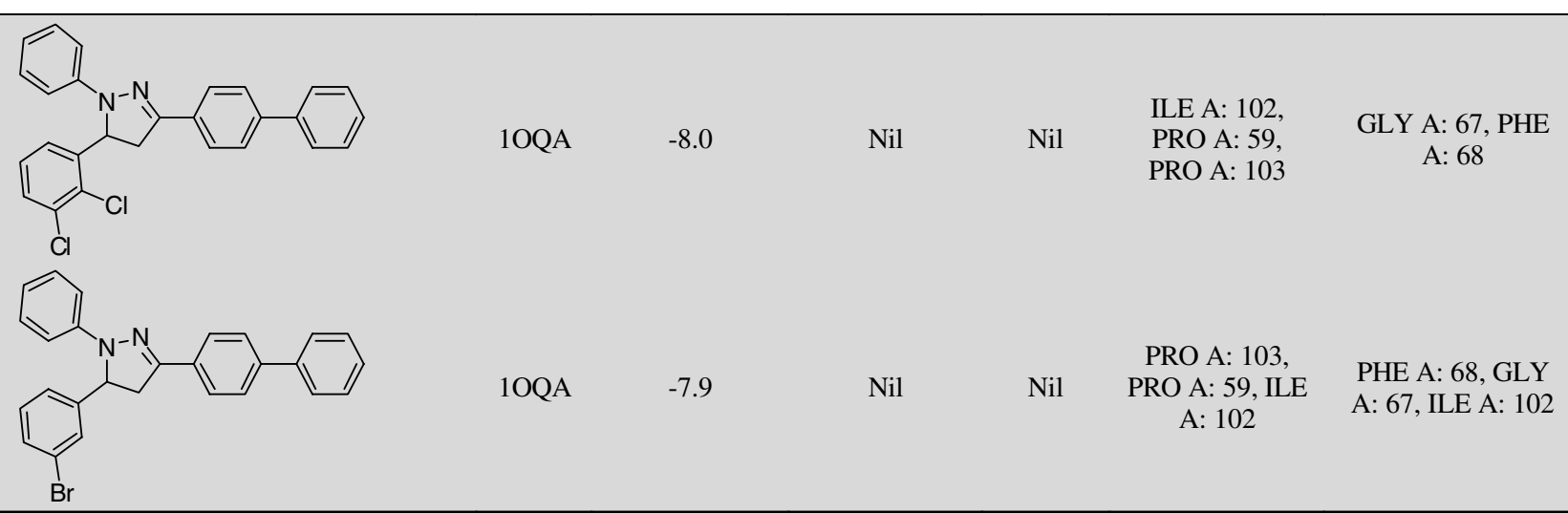

affinity score $(-8.8 \mathrm{kcal} / \mathrm{mol})$ compared to other compounds (2a-j) of this series. Other compounds binding affinity scores are shown in Table-2. Based on the high binding affinity score, compound 2d have three hydrophobic interactions (PRO A: 59, PRO A: 103, TYR A:100) formed with pyrazole moiety. Other compounds hydrophobic interactions are shown in Table-2. Based on this result, compound $\mathbf{2 d}$ wasperformed in vitro anticancer activity against MDA-MB-231 cell line.

Among the compounds (2a-j) subjected to in silico analysis against the bacterial cell wall proteins $1 \mathrm{UAG}, 2 \mathrm{X} 5 \mathrm{O}$ and 3UDI. Compound 2d showed good binding affinity score -9.6, -8.7 and $-11.1 \mathrm{kcal} / \mathrm{mol}$ when docked with these three proteins, indicating a very good affinity. In a similar way, these synthesized compounds (2a-j) were docked with the human breast cancer protein (1OQA). Compound 2d showed a binding score of $-8.8 \mathrm{kcal} / \mathrm{mol}$ and thereby indicated it is a good candidate for further studies. So in vitro studies (MTT assay of antimicrobial studies) were carried out to confirm its activities.

MTT assay: Based on high binding affinity score, compound 2d (4,5-dihydro-1-phenyl-3-diphenyl-5-(4-bromophenyl)- $1 \mathrm{H}$ pyrazole) were screened for in vitro anticancer studies (human breast cancer). The in vitro anticancer activity was performed by MTT assay method. It was done by various concentration $(100,50,25,12.5,6.25 \mu \mathrm{g} / \mathrm{mL})$ of compound $2 \mathrm{~d}$ against MDAMB-231 cell line. From this result, compound 2d showed moderate activity in all concentration except $6.25 \mu \mathrm{g} / \mathrm{mL}$. The $\mathrm{LC}_{50}$ value for this compound is $-185.309 \pm 1.469 \mu \mathrm{g} / \mathrm{mL}$.
Antimicrobial activity: Antibacterial activity were screened for 2-phenylpyrazoline derivatives (2a-j) using different strains (S. aureus, Klebsiella, E. coli and Streptococcus) at different concentrations (100, 50 and $25 \mathrm{mg} / \mathrm{mL}$ ). The results are shown in Table-3. It is seen that all 2-phenylpyrazoline compounds showed a good zone of inhibition against these four strains.

At high concentration $(100 \mathrm{mg} / \mathrm{mL})$, compound $2 \mathbf{i}$ showed a good zone of inhibition (34 mm) against Streptococcus; Compounds $\mathbf{2 b}, \mathbf{2 d}$ and $\mathbf{2 i}$ showed a good zone of inhibition $(13 \mathrm{~mm}$ ) against E. coli; Compound $\mathbf{2} \mathbf{j}$ showed good zone of inhibition against Klebsiella strain (28 mm); Compounds $\mathbf{2 b}$, $\mathbf{2 d}$ and $2 \mathbf{i}$ have shown a good zone of inhibition $(13 \mathrm{~mm})$ against S. aureus.

At low concentration $(25 \mathrm{mg} / \mathrm{mL})$, compounds $\mathbf{2 b}, \mathbf{2 c}, \mathbf{2 d}$ and $2 \mathbf{i}$ shown good zone of inhibition $(10 \mathrm{~mm})$ against $S$. aureus; Compound 2a showed a good zone of inhibition $(15 \mathrm{~mm})$ against Klebsiella; Compounds $\mathbf{2 b}, \mathbf{2 c}$ and $\mathbf{2 d}(10 \mathrm{~mm}$ ) showed a good zone of inhibition against $E$. coli, while compound $2 c$ have shown a good zone of inhibition against Streptococcus.

Finally from these results, compound $\mathbf{2 i}$ (2,3-dichloro) substitution shown a good zone of inhibition at high concentration compared to other derivatives of this series (2a-j). At low concentration, compound $\mathbf{2 c}$ (fluoro substitution) shown a good zone of inhibition compared to other derivatives of this series (2a-j).

Antifungal activity: 2-Phenylpyrazoline derivatives were screened for antifungal activity at different concentrations (100,

TABLE-3

ANTIBACTERIAL ACTIVITY TEST FOR 2-PHENYL PYRAZOLINE DERIVATIVES WITH DIFFERENT STRAINS BY AGAR DISK DIFFUSION METHOD

\begin{tabular}{|c|c|c|c|c|c|c|c|c|c|c|c|c|}
\hline \multirow[b]{2}{*}{ Comd. } & \multicolumn{3}{|c|}{ S. aureus } & \multicolumn{3}{|c|}{ Klebsiella } & \multicolumn{3}{|c|}{ E. coli } & \multicolumn{3}{|c|}{ Streptococcus } \\
\hline & $\begin{array}{c}100 \\
\mathrm{mg} / \mathrm{mL}\end{array}$ & $\begin{array}{c}50 \\
\mathrm{mg} / \mathrm{mL}\end{array}$ & $\begin{array}{c}25 \\
\mathrm{mg} / \mathrm{mL}\end{array}$ & $\begin{array}{c}100 \\
\mathrm{mg} / \mathrm{mL}\end{array}$ & $\begin{array}{c}50 \\
\mathrm{mg} / \mathrm{mL}\end{array}$ & $\begin{array}{c}25 \\
\mathrm{mg} / \mathrm{mL}\end{array}$ & $\begin{array}{c}100 \\
\mathrm{mg} / \mathrm{mL}\end{array}$ & $\begin{array}{c}50 \\
\mathrm{mg} / \mathrm{mL}\end{array}$ & $\begin{array}{c}25 \\
\mathrm{mg} / \mathrm{mL}\end{array}$ & $\begin{array}{c}100 \\
\mathrm{mg} / \mathrm{mL}\end{array}$ & $\begin{array}{c}50 \\
\mathrm{mg} / \mathrm{mL}\end{array}$ & $\begin{array}{c}25 \\
\mathrm{mg} / \mathrm{mL}\end{array}$ \\
\hline $2 \mathbf{a}$ & 12 & 10 & 5 & 18 & 15 & 12 & 12 & 10 & 5 & 21 & 16 & 14 \\
\hline $2 b$ & 13 & 11 & 10 & 17 & $>10$ & - & 13 & 11 & 10 & 23 & 13 & - \\
\hline $2 c$ & 12 & 11 & 10 & 13 & $>10$ & $>10$ & 12 & 11 & 10 & 24 & 22 & 20 \\
\hline 2d & 13 & 12 & 10 & 16 & 11 & $>10$ & 13 & 12 & 10 & 20 & 13 & 11 \\
\hline $2 e$ & - & - & - & 12 & 11 & $>10$ & - & - & - & 20 & 18 & 17 \\
\hline $2 f$ & 10 & - & - & 24 & 11 & 10 & 10 & - & - & 25 & 13 & 12 \\
\hline $2 g$ & - & - & - & 24 & 14 & 14 & - & - & - & 30 & 20 & 18 \\
\hline $2 h$ & 11 & 8 & 5 & 20 & 15 & 13 & 11 & 8 & 5 & 32 & 27 & 16 \\
\hline $2 \mathbf{i}$ & 13 & 12 & 10 & 23 & 16 & 13 & 13 & 12 & 0 & 34 & 19 & - \\
\hline $2 \mathbf{j}$ & 10 & 5 & - & 28 & 16 & 14 & 10 & 5 & - & 22 & 13 & 12 \\
\hline
\end{tabular}

- which means there is no zone of inhibition. 
50 and $25 \mathrm{mg} / \mathrm{mL}$ ), the results are shown in Table-4. It is found that 2-phenylpyrazoline derivatives did not showed any zone of inhibition against Candida albicans.

\begin{tabular}{cccc}
\multicolumn{5}{c}{ TABLE-4 } \\
\multicolumn{5}{c}{$\begin{array}{c}\text { ANTIFUNGAL ACTIVITY TEST FOR 2-PHENYL } \\
\text { PYRAZOLINE DERIVATIVES (2a-j) }\end{array}$} \\
\hline \multicolumn{4}{c}{ Antimicrobial susceptibility test against Candida albicans } \\
\hline \multicolumn{4}{c}{ Zone of inhibition (diameter in mm) } \\
\hline Compounds & $100 \mathrm{mg} / \mathrm{mL}$ & $50 \mathrm{mg} / \mathrm{mL}$ & $25 \mathrm{mg} / \mathrm{mL}$ \\
\hline $\mathbf{2 a}$ & - & - & - \\
$\mathbf{2 b}$ & - & - & - \\
$\mathbf{2 c}$ & - & - & - \\
$\mathbf{2 d}$ & - & - & - \\
$\mathbf{2}$ & - & - & - \\
$\mathbf{2}$ & - & - & - \\
$\mathbf{2}$ & - & - & - \\
$\mathbf{2}$ & - & - & - \\
$\mathbf{2}$ & - & - & - \\
$\mathbf{2}$ & - & - & - \\
\hline -w & - & - &
\end{tabular}

\section{Conclusion}

A new series of 2-phenylpyrazoline derivatives were synthesized and characterized by FT-IR, ${ }^{1} \mathrm{H}$ NMR and ${ }^{13} \mathrm{C}$ NMR spectral data. The synthesized compounds were screened for molecular docking studies using bacterial proteins and breast cancer protein. Among the synthesized compounds, compound 2d (4-bromo substitution) showed a good binding score and good binding interaction as compared to other derivative compounds. Thus, compound $\mathbf{2 d}$ was selected for the anticancer activity using MTT assay method, which showed a moderate activity of $\mathrm{LC}_{50}$ value $(185.30 \pm 1.469 \mu \mathrm{g} / \mathrm{mL})$. The antimicrobial activity was screened for synthesized 2-phenylpyrazoline derivatives (2a-j). The fluoro substituted compound (2c) have shown a good zone of inhibition at low concentration against $S$. aureus and 2,3-dichloro substitution showed a good zone of inhibition at high concentration $(100 \mathrm{mg} / \mathrm{mL})$ against Streptococcus.

\section{CONFLICT OF INTEREST}

The authors declare that there is no conflict of interests regarding the publication of this article.

\section{REFERENCES}

1. M.J. Ware, S. Tinger, K.L. Colbert, S.J. Corr, P. Rees, N. Koshkina, S. Curley, H.D. Summers and B. Godin, Sci. Rep., 5, 12083 (2015); https://doi.org/10.1038/srep12083.

2. K. Lukasiewicz and M. Fol, J. Immunol. Res., 2018, Article ID 2397808 (2018); https://doi.org/10.1155/2018/2397808.

3. B. Semire and A.K. Oyebamiji, Bull. Pharm. Res., 7, 150 (2017); https://doi.org/10.21276/bpr.2017.7.3.3.

4. S.S. Abd El-Karim, M.M. Anwar, N.A. Mohamed, T. Nasr and S.A. Elseginy, Bioorg. Chem., 63, 1 (2015); https://doi.org/10.1016/j.bioorg.2015.08.006.

5. E. El-Sawy, A. Mandour, K. Mahmoud, I. Islam and H. Abo-Salem, Acta Pharm., 62, 157 (2012);

https://doi.org/10.2478/v10007-012-0020-3.

6. Z. Lin and J.-T. Li, E-J. Chem., 9, 267 (2012); https://doi.org/10.1155/2012/364798.

7. R. Gupta, N. Gupta and A. Jain, Indian J. Chem., 49B, 351 (2010).

8. S.D. Tupare, S.A. Dake, S.V. Nalage, S.V. Bhosale, R.D. Ingle and R.P. Pawar, Int. J. Org. Chem., 2, 371 (2012); https://doi.org/10.4236/ijoc.2012.24051.

9. S. Hassan, Molecules, 18, 2683 (2013); https://doi.org/10.3390/molecules 18032683 .

10. R. Chinnamanayakar, M.R. Ezhilarasi, B. Prabha and Kulandhaivel, Asian J. Chem., 30, 783 (2018); https://doi.org/10.14233/ajchem.2018.20992.

11. R. Sri Dharani, R. Ranjitha, R. Sripathi, K.S. Ali Muhammad and S. Ravi, Asian J. Pharm. Clin. Res., 9, 121 (2016); https://doi.org/10.22159/ajpcr.2016.v9i5.12693.

12. L.B. Talarico, R.G.M. Zibetti, P.C.S. Faria, L.A. Scolaro, M.E.R. Duarte, M.D. Noseda, C.A. Pujol and E.B. Damonte, Int. J. Biol. Macromol., 34, 63 (2004);

https://doi.org/10.1016/j.ijbiomac.2004.03.002. 